\title{
Community-led initiatives' everyday politics for sustainability - conflicting rationalities and aspirations for change?
}

Anke Fischer ${ }^{1 *}$, Kirsty Holstead ${ }^{1}$, Cary Yungmee Hendrickson ${ }^{2}$, Outi Virkkula ${ }^{3}$, Alessandra Prampolini $^{4}$

${ }^{1}$ Social, Economic and Geographical Sciences, James Hutton Institute, Craigiebuckler, Aberdeen AB15 8QH, Scotland, UK

${ }^{2}$ Department of Methods and Models for Economics, Territory and Finance (MEMOTEF), Università di Roma “La Sapienza”, via del Castro Laurenziano 9, 00161 Rome, Italy ${ }^{3}$ Oulu University of Applied Sciences, Kotkantie 1, 90250 Oulu, Finland ${ }^{4}$ T6 Ecosystems srl, via Genova 30, 00184, Rome, Italy

*Corresponding author: Phone: +44 (0)1224 395299; Email: anke.fischer@hutton.ac.uk

\begin{abstract}
Community-based initiatives are widely seen to play an essential role in a societal move towards a low carbon, sustainable future. As part of this, there is often an assumption that such initiatives share expectations (i.e., a guiding vision) of large-scale change, and that their activities contribute to this change. Here, we ask to what extent this assumption reflects members' own perspectives on and interpretations of the visions, aims and ambitions of their community initiative, and what this implies for a larger vision of sustainability transitions. In doing so, we respond to calls for a better understanding of the "everyday politics" of what could be seen as processes of societal transitions in practice.
\end{abstract}


We conducted qualitative interviews with members of five community initiatives in Italy, Finland and the UK. In each of these initiatives, we found a range of aspirations (i.e., outcome-related aims) and rationalities (i.e., procedural guiding principles). While some of these aims and ways of working were compatible with each other, we identified three major tensions that could be found across our study initiatives. These tensions centred on (i) the degree of politicisation of the initiative, (ii) the extent to which financial aims should take priority, and (iii) questions of organisational form. We interpret these tensions as conflicting expressions of larger, societal-level discourses, and argue that this diversity and resulting conflicts need to be acknowledged - both in transition research and at the practical level - to avoid co-optation and disenfranchisement.

Key words: discourses; expectations; grassroots; low carbon; transitions

\section{Introduction}

Community action and grassroots initiatives are widely seen as essential in the endeavour towards a low carbon future and a more sustainable society and economy overall in both academic (Middlemiss and Parrish, 2010; Parkhill et al., 2015; Van der Schoor and Scholtens, 2015) and applied debates (Hopkins, 2008). As part of this, there is often an assumption that such community-led initiatives share a vision of large-scale change (Shove and Walker, 2007), that their actions build up to a larger movement (Seyfang and Haxeltine, 2012), and that the resulting change (or 'transition') can be engineered - or at least steered in the direction of this guiding vision (Shove and Walker, 2007). Here, we ask to what extent this assumption reflects members' own perspectives on and interpretations of the visions, aims and ambitions of their community initiative, and what this implies for a larger vision of sustainability transitions. 
To date, case studies of grassroots sustainability initiatives, i.e., of civil society-led organisations contributing to the sustainability agenda, have described a wide range of social, economic and/or environmental aims, including economic benefits (Haggert et al., 2013; Seyfang et al., 2013), community autonomy and self-governance (Bomberg and McEwen, 2012), justice and inclusion (Ferris et al., 2001; Baker, 2004), public participation and social learning (Levkoe, 2006), and environmental protection and moving to a low-carbon society (Middlemiss and Parrish, 2010; Seyfang and Haxeltine, 2012). Even within a single domain such as community-based energy projects, the broad range of activities and objectives of the different organisations can make it difficult to identify a common denominator (Seyfang et al., 2013). Such studies, while revealing diversity across initiatives, usually do not tend to investigate diversity within an initiative.

Other research has looked at the range of individually-held motivations that led members of initiatives to join (Hibbert et al. 2003; Seyfang and Haxeltine 2012), but while it is widely recognised that personal motivations to join or stay involved in a collective activity vary within a group (Pagès et al., in press), these personal motivations might be very different from an individual's perspective on the aims and ambitions of the initiative (Foden, 2012). For example, a person might be motivated to join a sustainability initiative by the prospect of meeting like-minded others, but not consider this social function to be the main aim of the initiative and instead recognise its ambition to increase the amount of low-carbon electricity provided to a neighbourhood.

Here, we examine the aims and ambitions of sustainability initiatives as seen by their members, including the relationships between these aims, the ways in which they are negotiated, and the implications of potential conflicts between aims. We recognise that while not all initiatives have formalised and explicit 'visions', 'missions' or objectives, they will 
have implicit ideas of their aims as well as reasons for their ways of working - however, these might not be consensually shared by all members of an initiative.

\section{Theoretical background}

Our study complements work in the context of 'transition management', which places niche innovations in an overall systems perspective (Kemp and Loorbach 2006; Geels 2011; Hargreaves et al. 2013). While this body of literature effectively represents a panacea for conceptualising the emergence of large-scale change (Shove and Walker 2007; Geels, 2011; Smith et al., 2010), some have criticised it for focusing on technological innovation and thus neglecting social and cultural aspects of change, and related to this, for an insufficient consideration of citizens and civil society beyond policy and corporate actors (Genus and Cole 2008; Shove and Walker 2010; Seyfang and Haxeltine 2012). Here, we contribute to the literature on social aspects and citizen engagement in the context of transition and niche management that has recently begun to emerge in response to such critique. In particular, our work is relevant for the understanding of 'expectations', a central term in this body of literature that denotes cognitive rules, imaginings and visions that "guide activities, provide structure and legitimation, attract interest and foster investment” (Borup et al. 2006: 285-6; Geels and Raven 2006). The role of expectations in socio-technological innovation has attracted attention from multiple social scientific perspectives (Borup et al. 2006), with the concept almost acting as a placeholder for very different understandings of such expectations, dependent on theoretical perspective and level of scale considered (see Konrad 2006 for examples). However, only a fraction of this work has been explicitly related to sustainability innovation.

In addition, while it is recognised that expectations might diverge between the projects that together form a niche for innovation (Seyfang et al. 2014), there appears to be a pervasive 
implicit assumption that within any one project or initiative, expectations are uniform and homogenous. And although the importance of shared expectations within a project or initiative in order for it to succeed is sometimes highlighted (Geels and Raven 2006), the question of how such shared and coherent expectations develop and are negotiated in practice is hardly ever addressed in the recent literature on social aspects of sustainability innovations. This also holds for recent work (Smith et al. 2016) that distinguishes between three different types of niche-based innovation: strategic niche management, niche policy advocacy and critical niches. While the authors use these as analytical perspectives, they can also be understood as rationalities adopted by different initiatives vis-à-vis their political and cultural contexts. But again, divergences, contestation and struggle within initiatives are not explicitly considered.

Our analysis will also provide insights into the interactions between expectations at the initiative level and those located in the wider, external context, as suggested by Geels and Raven (2006:390). Such meso- or macro-level expectations (Borup et al. 2006) have been described as collective expectations that are general, abstract and depersonalised (Konrad 2006). Here, we will use the concept of discourses (i.e., ensembles “of ideas, concepts, and categories through which meaning is given to phenomena”; Hajer, 1993) to conceptualise such collective expectations within a well-established theoretical framework, and to explore links between the diversity of aims and ambitions within initiatives and overarching societal discourses. Discourses have occasionally been mentioned in relation to niche-based innovation (Smith et al. 2016), but are hardly ever explicitly considered in relation to conflicts and contestation within initiatives.

As we will see, our understanding of 'expectations' or, more generally, the aims and ambitions of an initiative, will be grounded in the empirical material. In this respect, our study is of relevance for the literature on transitions and niche management, but does not 
adopt such a perspective in itself. We argue that our approach that openly and critically examines the (potential) diversity of aims within grassroots sustainability initiatives is important, as it allows us to interpret these initiatives in their wider socio-political contexts, including the institutional and discursive contexts that shape them, and to examine the "cultural, ecological, economic, political and philosophical models which inform these initiatives” (Tornaghi, 2014: 12-13). By investigating the ambitions of those who are expected to 'do' transition and attending to the dynamics and heterogeneity within community-led initiatives, drawing on insights from five initiatives in three countries, we take a grassroots perspective that complements the abstract and technological approach provided by the multi-level perspective, and that, in spite of recent advances towards a stronger consideration of grassroots actors and socio-cultural factors, seems to still view an initiative or project as a homogenous unit. In doing so, we study the micro-politics of sustainability transitions, an area which has previously been neglected (Shove and Walker, 2007; Scrase and Smith, 2009; Markard, Ravel and Truffer, 2012). We investigate how initiatives' "everyday politics” (Shove and Walker, 2007) are played out in practice, and how they relate to larger visions of societal transitions as envisaged by protagonists of the transition movement (Hopkins, 2008; Sarkissian et al., 2009), and conversely, to the criticisms of exclusionary mechanisms, persistence of social inequalities and neoliberalism levelled at grassroots initiatives (Ghose and Pettgrove, 2014; Rosol, 2014; Tornaghi 2014).

\section{Methods}

\section{Approach}

The qualitative study presented here was part of the interdisciplinary research project TESS (Towards European Societal Sustainability) funded by the European Union's Framework Programme 7. It was designed by a wider team of project participants with the explicit aim of 
developing an understanding of community-based sustainability initiatives based on the initiative members’ own perspectives. 'Sustainability’ was here broadly understood as a guiding principle that entails the consideration of environmental, social and economic aspects for both current and future generations (UNCSD, 2012). In this study, we wanted to explore what success and impact meant to those who participated in community sustainability initiatives, how they experienced the development of their initiative, and if and how they situated their work within a wider societal context.

Jointly, with a team of researchers from six European countries, we designed a methodology that centred on loosely structured qualitative interviews with members of community-based sustainability initiatives and key actors related to the initiatives' activities. These interviews followed a shared guide that was pretested in all study areas, subsequently refined, and where possible complemented by (participant) observation of the initiatives' work, including their meetings. Key interview questions focused on the interviewee's views on the history, aims and visions of the initiative, its participants and the factors that influenced its development over time. Towards the end of the interview, we explicitly probed the interviewees on whether they saw their initiative as contributing to larger social and/or political change. All interviews were audio-recorded and transcribed verbatim in their original languages.

\section{Sampling}

In our analysis, we draw on the perspectives of 35 interviewees from five initiatives, situated in three European regions (Scotland, Rome in Italy, and Southern Finland; see Table 1). As our analysis aimed to explore diversity in aims and ambitions and the ways in which these are negotiated, we selected these initiatives to cover broad range of aspects including organisational forms, domains (e.g., food, energy, transport) and social and political contexts. The selection of community-based initiatives (hereafter: initiatives) was based on a mutually 
agreed upon set of criteria: (a) They operated in a field relevant to the sustainability debate, although explicit self-identification with sustainability-related aims was not required, (b) they existed for a minimum of one year, and (c) irrespective of their current organisational form, they were firmly rooted in and provided a service to a community of place.

The study presented here involved, first (see Table 1), a development trust from a rural town in Scotland. This ‘Community Coalition' (all names of organisations and individuals are pseudonyms) had evolved from an organisation affiliated with the Local Authority and was now an independent trust. Its most recent activities involved the acquisition of a farm as a place for community activities, and the - very onerous and financially risky - application for a wind turbine, which, it was hoped, would make the trust on the long run less dependent on external funding. Since its beginnings as a project supported by the Local Authority, the trust had been managed by the same full-time employee. A board of directors provided direction and were personally financially responsible for the economic fate of the trust. Active members engaged in working groups that, for example, developed concrete plans for the management and use of the community farm.

Second, we included 'Students for Sustainability', a set of student initiatives at a Scottish university, which included a volunteer-based food co-operative/café that also provided space for the preparation of political campaigns, and an energy saving project run by paid staff and interns. Both were housed in the building of the student association under the auspices of an elected student committee for ethics and the environment and there was some (albeit limited) overlap in membership, but as we will see (Section 'Links between tensions'), had fundamentally different understandings of their activities, aims and ambitions. Third, in southern Finland, we worked with 'Ruokaosuuskunta', a community-supported agricultural co-operative, a membership organisation that relies on member fees and work 
contributions, complemented by two paid staff during the growing season and various shortterm helpers. The co-op then distributes its harvest equally among its members.

Fourth, 'Casa Verde’ in Rome, Italy, has been running a wide range of activities (see Table 1) for more than 20 years, from urban gardens and a farmers’ market to an organic restaurant, to a public Green Library, which is unique in the local context. The association emerged from a history of social struggle of a working class neighbourhood in the 1960s and 1970s which led to environmental protection activities in the 1980s in the face of urbanisation plans that were perceived as aggressive and threatening. Casa Verde eventually secured the use rights over 50 ha of abandoned land and an old farm building, which now forms a long-term basis for its manifold activities.

Fifth, 'Ciclomania', in Rome, is a bike workshop and community centre providing free access to bike parts and tools, aiming to promote and mainstream cycling as a means of transport. Ciclomania exists since 2004 and is one of about 16 of such community workshops in Rome, which all vary in their activities and outlook, ranging from collaboration with the local administration to open confrontation and contestation of the existing conditions. Ciclomania itself developed from a squatted social centre in central Rome, evicted by the municipality in 2006. Since then, the initiative has been collaborating with the municipality in many respects, and uses, for example, workspace owned by the municipality for a very low rent. Within each of these initiatives, we strived to speak to a wide range of people, including founding members, office bearers (where relevant), 'ordinary' and more recent members, individuals who benefitted from the work of the initiative but were not necessarily members, and other, closely related actors where relevant. All interviewees were encouraged to speak as individuals, and not as representatives of their organisation or office.

\section{Data analysis}


Interviews were conducted between November 2014 and May 2015, followed by an exploratory analysis based on written impressions that were structured according to the initial, broad research questions, but that at the same time also allowed us to take a step back, to explore the interviews in a grounded manner, and to consider unexpected outcomes (Strauss and Corbin, 1990). These exploratory summaries were discussed at a project meeting where the theme of 'aspirations and rationalities' (i.e., outcome-related and procedural aims of an initiative), and related to this, the initiatives' diversity and the negotiations of the tensions between conflicting aims of an initiative in practice, emerged as prominent and relevant in a number of the study cases.

We then developed a simple coding framework, including jointly defined categories such as “aspirations”, “rationalities”, “emerging tensions” and "processes of negotiation” to examine these questions in more detail. The latter two categories referred solely to tensions and negotiations related to aspirations and rationalities (e.g., tensions emerging purely from different management practices or personal relationships were not included), a distinction that was in practice relatively straightforward to implement. To prepare for the coding of the interviews, transcripts from the Scottish cases were used to test the coding framework and to develop a joint understanding of the core ideas that would collectively form the analysis. All authors then thematically coded their interviews with the help of the software package for qualitative data analysis NVivo and shared detailed analytical summaries of their interviews, organised according to the coding categories, and written in English. A one-week writing workshop with the team of authors helped to explore, consolidate and refine the emerging findings.

\section{The multiplicity and diversity of aspirations and rationalities}


Our presentation of the results is organised as follows: We begin with an overview of the diversity of aspirations and rationalities expressed in our interviews, and then identify three types of tensions that appeared to be widespread among our study initiatives. We explore how these tensions were negotiated in practice, and finally, how they could be interpreted as reflections of larger societal discourses, which might explain these tensions to some extent.

\section{Two types of aims: procedures and outcomes}

Our interviewees articulated two types of aims in talking about their initiatives: (i) outcomerelated aims (hereafter referred to as 'aspirations'), and (ii) more procedural guiding principles (hereinafter, referred to as 'rationalities'). We consider aspirations as related to relatively broad aims for behavioural, social, economic or political change, while rationalities expressed interviewees' views on the initiative's way of working in order to achieve its aspirations. Rationalities, thus, encapsulated an internal logic that, from the interviewee's perspective, underpinned the initiative's course of action.

Empirically, aspirations and rationalities could overlap where the means to an end (the rationality) were also seen as an end in itself (an aspiration). For example, the logic of making an initiative financially resilient in order to decrease dependence on small-scale grants (often considered too unpredictable), could become an aspiration in and of itself. Both aspirations and rationalities were embedded in and shaped by the social, political, economic and environmental contexts in which the initiatives acted; however, here, we abstract from these for the time being (returning to broader discursive contexts in 'Links between tensions') to take a comparative look at the micro-level dynamics with which the initiatives negotiated their diverse aims. In a first step of our analysis, the following sections illustrate the diversity of aspirations and rationalities across our study initiatives. 
On the diversity of aspirations

Aspirations put forward by our interviewees ranged from the material and pragmatic to the intangible and transcendent. At the more concrete end of the spectrum, for example, Ciclomania, Ruokaosuuskunta and the student food co-op aimed at improving the provision of transport options and healthy and sustainably sourced food, respectively. Some initiatives also strived to change individual behaviour (e.g., the student energy initiative, the fuel use campaign of the Community Coalition, and Ruokaosuuskunta):

[...] with biodynamic farming we also introduce new ways of consumption, new taste experiences to people and new raw ingredients. (ROK-Pekka-founding member-M$40)^{1}$

Economic survival and the financial sustainability of the initiative could each be an end in itself and seemed to be particularly strongly expressed in the Community Coalition and Ruokaosuuskunta (see below). Other aspirations lay at a more procedural level, such as the desire to provide and maintain a space for joint activities and to meet like-minded people. At the less tangible end of the spectrum, some interviewees articulated their initiative's aims to work towards a more resilient, inclusive, just and sustainable community (Ciclomania, Community Coalition), but only Ciclomania expressly aspired to contributing to a better society at large. Indeed, there was often a focus on the local level, and for some of our interviewees, making their immediate surrounding better was the essence of their initiative (Ruokaosuuskunta, Community Coalition). In some cases, a focus on the local could have arisen from a muted desire to create impact at a larger scale and the management of one's own expectations:

... what's happening right now on a global scale is not OK, and I...I don't like this approach of like 'It's so big we can't do anything', so I think everything counts. And

\footnotetext{
${ }^{1}$ Sources of quotes are labelled as follows: initiative label (see Table 1) - name (pseudonym) of interviewee type of member - gender - approximate age. F: female; M: male.
} 
we probably won't change the world here, but we do like really small things that help certain people and then maybe they get motivated too and achieve something in their town or something, so... (SfS-Anna-food coop-F-21)

For others, the dual nature of aspirations as simultaneously abstract and transcendent and concrete and local was still very salient:

In this association, we realised the need to make some ideas more concrete and to not keep working at a theoretical level only. (CV-Francesca-founder-F-65) Even when both perspectives were not shared by all initiative members, it seemed that they could be quite easily reconciled: More concrete and pragmatic goals could be nested under wider, more abstract aspirations. For Ciclomania, the concrete goal of increasing the number of cyclists in town was very much compatible with and, in fact, directly contributed to some interviewees' much more abstract aspirations to change the way natural resources were used at a societal level:

Others [think] that the bike could be a tool through which we can change the city, the country in general. Also to change the world... Basically the idea is that we can use the bike as a means to go against the oil industry, all that's connected geopolitically and the use of fossil fuel resources. (CM-Giuseppe-long-term member-M-38) In the student food co-op, while some members aspired to share their political ideas and develop campaigns, others saw the initiative simply as a space where students could provide themselves with healthy, sustainable food in the company of like-minded people, and this diversity in aspirations was accepted (but not necessarily actively supported) by both sides.

On the diversity of rationalities

Similarly, our interviewees articulated a wide range of rationalities (i.e., internal procedural principles) for the activities their initiatives are engaged in. While for some, aspirations could 
be achieved through living by example, showcasing alternatives to lifestyles that were seen as unsustainable, or by spreading knowledge about more sustainable options, others saw their initiative as working through direct political action. The extent to which relationships with governmental organisations were seen as helpful to achieve the initiatives' aspirations tended to be a key feature of their rationalities (see 'The role of organisational form').

Such rationalities were by no means static, and they were recognised as changing over time in response to the initiative's development in terms of, for example, members and funding, but also with respect to wider changes in society:

Twenty years ago, [...] it was vital that people descended onto the streets of the neighbourhood and defended the park: A more 'gut-level' approach you might say, more spontaneous and definitely less rational. This has been useful in stopping overbuilding and so on. Maybe today we are in a phase in which it is essential that along with an ideal vision there is also the ability to identify the 'legs', to evaluate feasibility and identify economic partners that can support [the initiative]. (CV-Stefano-founder-M-65)

\section{Three types of tensions}

However, although many of these diverse aspirations and rationalities co-existed in our study initiatives, this co-existence was not always without tension. Here, we describe three types of tensions that occurred in several of the initiatives, and could be traced back to differences in aspirations and/or rationalities (as opposed to tensions arising purely from other issues such as working styles, personal relationships or management structures as such) within an initiative. Such tensions ranged from difficult choices being discussed among the members (and sometimes, individuals even feeling divided about the different options and approaches themselves) to open conflicts between different parts of the initiative (or between individual members and the rest of the group). 


\section{Politicising the initiative's work versus an apolitical approach}

One of the key frictions arising was a tension between the desire to 'be political', i.e., to actively contest (parts of) the existing political, economic and societal system, and the wish to refrain from being overtly confrontational. While this tension was discussed in all our initiatives, it was particularly apparent among the Students for Sustainability which was, in itself, an amalgamate of several smaller and diverse organisations (Table 1), and it was along the boundaries of these different organisations that the rift became most evident. While having "a political edge” and a "critical voice” (SfS-Cameron-food coop-M-21) was seen as essential by several members of the food co-op, and was reflected in the campaigning activities of the group, the staff of the energy initiative suggested that change was to come about through “a lot of silent work” (SfS-Petra-energy project intern-F-27):

...not in campaigning, I'm not the sort of person who would, ehm, sort of chain herself to a tree. I believe more in like, ehm, sort of like, pushing for change on a more subtle level. (SfS-Mara-energy project staff-F-27)

Similarly, several of the interviewees from other initiatives, especially from Ruokaosuuskunta and the Community Coalition, argued that it was necessary to be deliberately apolitical to attract a wider range of participants, beyond those who were already active, as too radical views could scare potential members away.

In a different sense, being openly political could also mean that outsiders saw the initiative as aligned with a particular political party or grouping, and such associations were generally seen as to be avoided.

I'd say we're quite apolitical - we'll work with anyone... if it's, you know, for the right...for the right project you know, and for the right outcomes. [...] If we're to be seen as an independent organisation working for the good of the community, you 
know, if we align ourselves with any one particular...ehm...political...you know, if we start making alliances politically, ehm... (CC-Stuart-staff-M-35)

Lastly, there was the notion that contestation and resistance was not an effective means to foster change, and essentially futile and unhelpful:

I think there is no point in going against something; instead we should [...] put our energy towards positive, sustainable ideology and start for instance a food co-op [...] because that is where change can be achieved. When you begin to work sustainably, in a good way, in a respectful way [...] then the others start wondering 'but they are operating in such a way [...] maybe we ought to act accordingly'. It is futile to go for resistance [...]. I think it is a waste of energy. (ROK-Matti-stakeholder-M-45) It seemed that underpinning this tension, there were more fundamental diverging views on the mechanisms through which the current system could be changed:

I suppose it depends on how you think the world changes. You need people to keep filling in the paperwork and make sure that everything stays running... [...] But I think you need people to be visionary for meaningful change to happen. (SfS-Fraserfood co-op-M-26)

Working towards substantive aspirations versus ensuring the survival of the initiative These fundamental differences were also reflected in another pattern of tensions that recurred in our interviews, namely, the friction between an initiative's need to survive financially or in terms of its membership, and the original aspirations that drove its founding:

... it's been this sort of split personality organisation from day one - we've wanted to do these good things that everyone says they want to see happen [...] But at the same time, while trying to do all these good things, if we're going to survive as [an 
organisation] we have to be commercially viable, and, trying to do some of these things actually makes it very difficult (CC-Ross-staff-M-45)

The key challenge here revolved around the allocation of time and effort as resources put into fund-raising, accreditation and the administration of grants were seen to be taking away from activities that many regarded as the core of the initiative - namely the joint work towards the initiative’s original aims, whether they involved the provision of healthier food, the improvement of cycling conditions, or political campaigns. Where financial viability as an aim became too dominant, this tended to be seen as a distortion of the core aspirations, and as distracting from what the initiative was really about. In a similar way, there were concerns that working towards external recognition could become an end in itself that had neither an effect on nor much to do with the initiative's core aspirations:

[They do a lot that's] designed to sound good, but not actually do good. So you're chasing awards and you're chasing accreditation - which is sometimes necessary to make yourself look good - but that's all they do. (SfS-Simon-committee member-M25)

At the same time, some interviewees - and this was particularly prominent in the Community Coalition - argued that financial viability (referred to as 'sustainability' in the quote below) was paramount, and therefore also a legitimate basis for decisions on future activities: ... it has to be sustainable, and that... that is critical. So, therefore, we have to make some difficult decisions in terms of 'we're going to not please everybody' and therefore we have to then decide which route we're going and... we have to inform partners that 'Sorry, it doesn't fit with the overall model'. (CC-Michael-director-M70) 
By some members of the Coalition, especially those less strongly involved in decisionmaking, this approach was seen to contradict the essence of what a community initiative was meant to be about:

...the social stuff doesn't, on the whole, tend to bring in the income, so there's a tendency to push all that stuff to one side. But for me, that's kind of really key to what a community organisation should be trying to do. (CC-Fran-former member-F-50) In response to these concerns which were indeed shared also by some in the Coalition who prioritised working for financial sustainability, they argued that this was only temporary, and a necessary step in a longer process to create "breathing space” (CC-Ross) for those projects they set out to do. This thought was also echoed in Ruokaosuuskunta:

The main objective has remained the same, perhaps it has been sometimes forgotten or maybe [...] some things are not achieved right away, but one has to have a long term view and as the very first [thing] to get the economic side functioning. (ROKPekka-founding member-M-40)

And again, behind these divergences in aspirations and rationalities, there seemed to be larger divides in terms of broader worldviews and also personal backgrounds. In the Community Coalition, some key players were experienced businesspeople, who explicitly drew on their background and expertise in their management of the Coalition (and, perhaps also of relevance, were liable for its financial fate); a perspective that did not seem to align with the views of the ordinary members for whom the community as a social body was paramount. Among the 'Students for Sustainability', food co-op volunteers perceived the staff of the energy-saving project as having to follow their funder's logic that required detailed reporting of changes in Carbon emissions as a metric to assess the impact of the project. This was seen to divert their attention and absorb a large part of their time and effort, which could then not used for activities that the food co-op volunteers saw as more central to their aspirations. In 
both cases, the underpinning rationalities - a business logic in the Community Coalition, a strict public funding regime in the case of the students - were seen as at odds with the logic that others regarded as appropriate for their community-based initiative.

\section{The role of organisational form}

Not surprisingly, closely related tensions therefore also emerged around issues of organisational form. This included first, the question of what type of organisation the initiative wanted to be. In Ruokaosuuskunta, members appreciated the fact that they were a co-operative, as they saw it as much more flexible, resilient in the face of risks, and reflective of their aspirations and rationalities - which involved shared working and learning - than a private company, run for profit, could ever be. However, they realised that a co-operative such as theirs, without meaningful resources for administration, faced limits to growth. Ciclomania had debated taking money for their bike repair services and pay their mechanics, but decided against it as they did not see themselves as a "bike shop" - however, the resulting lack of resources was seen as a serious limitation by some.

There was a time when some proposed that we add a bit of profit to what we do, to create a cooperative that could finance the initiative...it caused really serious discussions because it seemed like we should become a bike shop. (CM-Giuseppelong-term member-M-38)

For the director of the board of the Community Coalition, the choice was obvious: Although it's a kind of social enterprise type organisation, it needs to be run as a sort of business - you can't do things that are gonna lose you money, you've got to generate money, you've got to generate surpluses, you've got to maintain employment... So, you need a certain amount of hard-headed business sense to run...I think to run it successfully (CC-Michael-director-M-70) 
This organisational form also found reflection in the Community Coalition's practices: We've become much sharper - much more action focussed - than we were. People who work in the public sector seem to use words like 'debate' and 'report' and 'consider' a lot, whereas those of the sort of private sector tend to think about 'action' and 'achievement' and 'doing'. (CC-Michael-director-M-70)

The choice of organisational form could be informed by the desire to distance oneself from another organisation, or conversely, to establish good relationships with these. The Community Coalition deliberately emphasised their (friendly) distance from the local authority - a governmental organisation they had previously been affiliated with and who still provides office space for the Coalition. By contrast, the two Italian initiatives, starting off in an environment where overt opposition to governmental bodies and squatting was commonplace, both decided to collaborate with the local authorities to avoid having to be constantly worried about eviction:

[We] did not waste time in defending the occupation. Because that is, in fact, a waste of time; you face someone whose only interest is to eliminate you. Hence it was our strategy to keep the administration in check so as to be able to start working, otherwise we would have spent years like that, nothing really... well, wasting our time. (CV-Francesca-founder-F-65)

However, such decisions had indeed caused tensions within the initiatives. In Ciclomania, for example, members who disagreed with the initiative's move towards an agreeable relationship with local authorities had left and gone to other, more radical cycling initiatives. In the Community Coalition, as we have already seen, members in less prominent positions strongly disagreed with the prevalent business logic of the Coalition that had been created by its board of directors. Among the Students for Sustainability, again, a rift ran along the boundaries of the two groups, with a volunteer-based co-operative seen as the organisational 
form that would best meet aspirations for the provision of a safe, informal and friendly space where like-minded people could meet. Closely related to this, debates therefore also revolved around the role of members, and included questions of professionalisation, volunteer retention and membership payments.

\section{Tensions enacted}

These tensions emerged in our initiatives in very different ways - while in some cases, they were only referred to as potential problems, in others, they caused more or less noticeable friction within the group. It seemed striking that in Ruokaosuuskunta, while the potential for the tensions identified here (see above) was recognised and commented on, the group seemed to have found ways to establish consensus. In the case of Ciclomania, several members who disagreed with the group’s aspirations or rationalities had moved to other cycling initiatives in the same city, and board members of the Community Coalition had left in disagreement with the director's approach. This was similar in Case Verde, where negotiation of the emergent tensions was, in addition, experienced as draining time and energy away from its core activities. In the students' food co-op, prospective members who felt excluded or intimidated by the dominant political view had simply not joined. No organisational structure seemed 'immune' to overt tensions, as they occurred in both relatively egalitarian set-ups, such as Ciclomania and the Students for Sustainability, and more formally structured and hierarchical ones, such as the Community Coalition.

Across our study initiatives, a range of communication approaches had been employed that, while they had likely played a role in generating tensions, had also helped to resolve or manage them. Not surprisingly, in-person meetings were probably the most important forum for negotiating conflicting aspirations or rationalities, as pointed out by interviewees from the student food co-op, Ruokaosuuskunta and Ciclomania. Where these mechanisms did not exist 
- for example, to bring the different groups within Students for Sustainability together tensions seemed to persist. However, even where meetings were scheduled whenever needed, such as within the students food co-op, we have little insight into how seemingly consensual and flexible decision-making as described below - and revealingly called "executive decisions" (Cameron) - might have eventually led to the withdrawal of participants who felt that their voice was not heard:

...there's always a space around here for things to get decided - it might be decided casually just in conversation... But eh... Yeah, so we kind of organise actions quite organically... (SfS-Cameron-food coop-M-21)

Existing decision-making structures - for example, in Ruokaosuuskunta or the Community Coalition - that, among others factors, were legitimised through knowledge, expertise and skills, could mean that power, as well as the effort spent, remained in the hands of a few, and change was inhibited:

It is obvious that he becomes tired, frustrated and bored with the fact that he needs to do this tremendous amount of work by himself, yet in the last meeting he was not able to name any tasks that he could share. The co-op is his baby, he has created this, and now he wants to be the one making the decisions. (ROK-Risto-member-M-46)

These findings illustrate how our study initiatives had adopted very different ways of negotiating divergences in aims and perspectives, and that such divergences had consequences that included participant drop-out and resignation. While these insights point towards implications for the practical management of such tensions (see discussion), they also contribute to a better understanding of the micro-politics of our study initiatives, in particular, how hegemonic aspirations and rationalities come to be asserted or - less likely renegotiated. 


\section{Links between tensions: Underpinning discourses}

The three types of tensions identified in our interviews were closely linked. For example, where an initiative was seen as having to grow in terms of its membership in order to ensure its viability (through membership contributions or the demonstration of impact), this was often connected to arguments that it could not be too radical or political, as this might put off prospective members that might come from a different, more mainstream segment of society. Similarly, explicit affiliations with, or dependencies on, other organisations, although potentially supporting the initiative’s economic survival through funding or in-kind support such as meeting space, could be seen as constraining the initiative in the expression and external communication of its aspirations and rationalities in terms of organisational form or political standpoint.

In addition, and as alluded to in previous sections, more fundamental differences in worldviews seemed to underpin the three tensions identified here. For example, there appeared to be a tendency that interviewees who argued for political action were more likely to object to a business logic and a focus on financial viability, whereas those who advocated business thinking tended to stay clear of contesting the current system.

Although we recognise that such links were not always observable, we propose here that such patterns arose as the aspirations and rationalities voiced by our interviewees were expressions of larger, and to some degree latent discourses that entailed implicit theories (or perhaps imaginaries) about how societal change towards sustainability could be achieved. These were situated at a much more abstract level than the initiative-focused views we elicited in our conversations, and our interviewees seemed to find it much easier to tell us about their experiences in the initiative than about their perspective on societal change at large. Members of the Community Coalition, for example, deliberately avoided talking about such larger perspectives, again, perhaps in part because they did not want to be seen as aligned with 
anything that could provoke controversy. However, occasionally, our interviewees did offer us an insight into the relationships between initiative-related aspirations and rationalities and larger discourses of societal change. Here, we illustrate these links as observed through the Students for Sustainability: Among its participants, we were able to discern three perspectives.

First, some of its members - especially among those working for the energy-saving project felt that societal change was needed, and could be achieved if people only had better knowledge about options for more sustainable behaviour: Based on increased awareness and information, people would change their behaviour, and this would effect the necessary change at a societal level. As two of our interviewees vividly explained, this view was rooted in their own experience in their Eastern European home countries, having observed substantial changes in people's behaviour (e.g., recycling) in response to the provision of information.

A second perspective was largely offered by members of the student food co-op who concurred that societal change was needed, but argued that more systemic and radical change was required, and that working towards individual behaviour change was insufficient as it was just "lifestyle-esque” and essentially a "cop-out” as “once you put it down to the individual then there's no societal problem" (SfS-Simon-committee member-M-25). These students argued for abandoning the "capitalist paradigm”, saw themselves as political and left-wing and, in line with this, had deliberately chosen the organisational form of a cooperative, as they considered this to be the most acceptable approach to the distribution of goods within the existing system. At the same time, they recognised that, in practice, the changes that they would implement if they had more political power would probably be much more moderate, locally-focused and concrete than their abstract debates suggested. 
Third, some interviewees appreciated that other members of the student food co-op might have larger-scale aspirations and political views but, for them, the initiative was just about its most tangible aspects: food and pleasant people.

Therefore, it seemed that these larger discourses provided normative guidance for our interviewees and embedded their views on the aspirations and rationalities of their initiative in a wider context. This also applied to our other study initiatives where similar discursive motives echoed through our interviewees’ talk. For example, this Casa Verde member objects, like the student quoted above, to an undue reliance on individual behavioural change as a pathway to larger transformations:

This bottom-up approach to these kinds of [sustainability] problems presents some risks. [...] It is also equally dangerous to give false perspectives. That is, I collect waste differently and I saved the environment. I turn off the lamp and I have done my part. This attitude is very common but it is terrible because it removes responsibility. If I think there is an easy way to address and resolve complex problems, I am making a mistake. (CV-Stefano-founder-M-65)

In Ruokaosuuskunta, several members argued, in a variation and extension of the discourse of individual behavioural change, that contestation, "preaching” and political engagement were not a likely way to achieve change. Rather, initiatives should invest their energies in developing positive, more sustainable approaches as an example for others, which would then speak for themselves and convince others to follow.

Although many interviewees found it challenging to talk about these larger underpinning discourses and what they meant for the everyday work of the initiative, some clearly saw links between these discourses and emerging tensions, as they explicitly criticised the dominance of the guiding discourse in their initiative and the almost ideological character that this seemed to have: 
The meaning of being a people's bike workshop means that we give what we have to everyone, it's very leftwing, like we give everyone the chance to have a bike ... and I agree with this but sometimes people see money like a bad thing, we have to keep the cash flow low because if we become rich, well, then we'll be bad people, and I don't really agree with this. (CM-Nico-new member-M-28)

\section{Discussion}

Our analysis set out to explore how participants in community-led sustainability initiatives see their initiative’s aims and ambitions, taking into account that there might be diversity within (as well as between) initiatives, thus contributing to a better understanding of the “everyday politics” (Shove and Walker, 2007) of what could be seen as processes of societal transitions in practice.

We found, first, that even within initiatives, actors diverged in terms of the various aspirations (i.e., outcome-related aims) and rationalities (i.e., procedural guiding principles) they ascribed to their initiative. While this seems hardly surprising, such divergences and diversity have only rarely been acknowledged in the literature on grassroots action and niche management to date (see 'Theoretical background'). Our finding lends support to the call for a multi-dimensional (rather than one-dimensional) assessment of the 'success' of an initiative (Baum, 2001), as success will, in many initiatives, not be consensually defined. It also raises further questions on the degree to which these manifold aspirations and rationalities together might or might not form a meaningful vision for societal transitions (Shove and Walker, 2007).

Second, we found that while some aspirations were experienced as compatible with each other, for example, because they could be seen as nested within each other (Section 'Diversity of aspirations') - a phenomenon also described by Bettencourt et al. (1996) -, 
there were tensions that recurred across our study initiatives. These seemed to be genuine tensions between differing aims and ambitions as attributed to the initiative, rather than conflicts between personal motivations and collective aims. Three types of tensions were identified: (a) Divergences over the degree to which the initiatives should be political, (b) disputes over the extent to which rationalities of financial viability should take precedence over its original aims and (c) frictions arising from choices of organisational form and affiliation. We suspect that these tensions are likely to be found also in other, similar community-led sustainability initiatives (and that our findings are thus to some extent transferable), but do not claim that the list of tensions found here is exhaustive by any means. Some of these tensions have indeed been described elsewhere, for example, as a distinction between 'simple' (working at a concrete and tangible level) and 'strategic' niches (seeking regime changes and wider transformation; Seyfang and Smith 2007; Seyfang et al. 2014). Smith et al. (2016) differentiate between three understandings of the relationships between grassroots innovation and dominant discourses that range from gradual institutionalisation of an innovation to open contestation and larger transformative processes. However, again, these analyses tend to be applied to differences between initiatives (or entire niches), rather than as an approach to understand dynamics within initiatives.

With our spotlight on intra-initiative divergences and tensions, our analysis addresses Shove and Walker's (2007: 768) concern that research on transition management might be “smoothing over conflict and inequality; working with tacit assumptions of consensus and expecting far more than participatory processes can ever hope to deliver”. Seyfang and Haxeltine (2012: 390), defining sustainability initiatives as grassroots innovation niches, remark that disparities between expectations “can be a source of disappointment for activists” and reduce the prospects of niche development (Kemp et al., 1998). Our findings unpack the nature of such disparities and conflicts. They highlight that grassroots initiatives should be 
understood as places of struggle, not necessarily unified and potentially much more precarious than commonly seen, not least because of the potential effects of such tensions on membership (see 'Tensions enacted'). Our analysis also suggests that clashing rationalities, often interpreted as conflicts between a (homogenous) initiative and external context, for example, where funding pressures constrain the activities of an initiative (Seyfang and Smith 2007; Seyfang and Haxeltine 2012), might be in many cases firmly located within the initiative itself (rather than at the interface between initiative and external context). However, although consensus and shared visions are usually seen as one of the foundations of thriving community initiatives (also beyond the niche management literature, see Sarkissian et al., 2009; Parkhill et al., 2015), and indeed, some of our study initiatives had lost members because of diverging aims and ambitions (see 'Tensions enacted'), we propose here to explore the role of tensions between different aspirations or rationalities also in terms of their potential to stimulate creative and constructive processes of change. First of all, disputes and disagreements over aims and ways of working are probably best seen not as failure, but as an integral part of the work of a community initiative. Constructive engagement with diverging aspirations and rationalities can lead to reflexive adaptation of the way an initiative works, but will also help to not lose sight of the aspirations that are considered to be at its core. This requires time (Sarkissian et al., 2009) and the appropriate fora. By contrast, in the absence of such fora, in the Community Coalition, for example, financial viability can be used by empowered individuals as a knock-out argument, which can ultimately lead to disenfranchisement of those members who do not share the logic of economic survival that is being privileged by those decisions. Future research could examine the consequences of divergences in aims and mechanisms to deal with such tensions in more depth, not least to further elucidate the role of power and influence in the 'everyday politics' within grassroots initiatives. 
At the same time, our study illustrates the consequences that changes in rationalities or aspirations, imposed, for example, by funding schemes and their requirements for project organisation and reporting (Aiken, 2014), might have for the internal dynamics of a community initiative. In the Students for Sustainability’s case, such funding requirements exacerbated a division in both rationalities and aspirations that, at the time of the interviews, its members found difficult to reconcile. Future research could examine the organisational structures and governance arrangements within and around such initiatives, and their implications for the ways in which aspirations and rationalities are negotiated. In our analysis, we distinguished, in a grounded fashion, between two types of aims, a more outcome-related (labelled aspirations) and a procedural type (labelled rationalities) (see also the distinction between 'outcome' and 'process' dimensions of community renewables projects, Walker and Devine-Wright 2008). While aspirations could be described as “people’s senses of viable future possibilities” (Zipin et al., 2015: 231) or “desires to achieve something in the future, with the implication that they will drive actions in the present” (Kintrea et al., 2015: 666-667), 'rationality' is probably best defined as an internal logic (Landini et al., 2014). Rationalities serve to legitimise an approach (Rydin, 2003), and can, as we have seen, emerge from as (not necessarily conscious) responses to institutional, economic or social contexts (Moore and McKee, 2013) - whether these are funding regimes or discourses of change. As we have shown, aspirations and rationalities cannot always be neatly distinguished from each other. However, we argue that this distinction is still useful as, first, it offers some degree of conceptual clarity in a field that seems surprisingly void of an explicit and in-depth analysis of community initiatives' aims and ambitions (see Seyfang et al., 2013; Walker and Devine-Wright 2008 for exceptions). Second, this distinction helps us to identify underpinning discursive components that reflect important aspects of larger 
worldviews and societal discourses, and related to this, the basis of a shared identity and meaning of the initiative (Bettencourt et al., 1996; Bomberg and McEwen, 2012).

We found that tensions between aims of an initiative could often be usefully understood as rooted in different discourses of societal change. Within the three discourses 'ecological modernisation', ‘green governmentality’ and ‘civic environmentalism’ identified by Bäckstrand and Lövbrand (2006), the core of the conflict among the Students for Sustainability seemed to emerge from a confrontation between reform-oriented and radical resistance interpretations of civic environmentalism (Bäckstrand and Lövbrand, 2006: 56). This points at differences in worldviews that might be difficult to turn into consensus, although, with mutual recognition and respect, both could continue to co-exist in parallel. This holds especially where, as suggested by some of our interviewees from the student food co-op, the adoption of a stance of prefigurative politics (Foden, 2012) implies that the ends do not justify the means, but that an initiative's rationality should reflect its aspirations at any time. We also recognise that in some initiatives, rationalities and aspirations might be adopted not necessarily because they reflect their members’ worldviews, but precisely to signal affiliation with or distance to a certain discourse, for example, in order to attract a wider range of members, secure funding from sources with specific requirements, or avoid losing support of a specific group.

\section{Conclusions}

Our analysis suggests that the imaginary of a sustainability transition might in practice be less shared than commonly assumed (Shove and Walker, 2007), as even within initiatives, the everyday politics of enacting a community initiative are characterised by plurality of perspective, negotiation, struggle and sometimes open contestation. Neither single initiatives nor entire niches (consisting of several initiatives, Seyfang et al. 2014) should thus a priori be 
regarded as homogenous. This raises the question as to whether it is ethical and realistic to co-opt these initiatives and their diverse members for a transition agenda that is often presented as consolidated and unified. We argue that a micro-perspective on the dynamics internal to initiatives and niches is important not only because it helps us to understand their trajectories, success and failure, but also, because an understanding of initiatives as places of struggle and inherently plural changes our general perspective on sustainability transitions towards that of a hybrid, socially negotiated and complex process of simultaneously emerging changes at multiple levels. Our study thus makes an empirical contribution to the critique of a hierarchically controlled and potentially anti-democratic understanding of sustainability transitions, which can be contrasted to a conceptualisation of societal change as diverse, multi-faceted, emergent and self-coordinating processes of transformation (Stirling 2014).

By recognising community initiatives as places of struggle and negotiation, instead of conceptualising them as unified and static, we also add to the critical perspective proposed by Tornaghi (2014) for urban agriculture initiatives. We argue that rather than a diagnosis of community groups as reproducing traditional capitalism and/or neoliberal forms of governance (Tornaghi, 2014), what is needed is a more nuanced look at the discourses, processes and conditions that shape initiatives' aspirations and rationalities, and the practices and impacts that develop from these.

Our findings also have practical implications (see discussion), as tensions can be both an opportunity and a threat to the often precarious existence of an initiative. Acknowledging tensions and establishing ways to constructively discuss and manage divergences through appropriate fora might help to develop a fruitful co-existence of plural aims and ambitions even where consensus might not be possible. At the same time, our study lends some support to research that suggests that public funding schemes need to consider how their rationalities 
impact on those of the initiatives that they aim to support (Aiken, 2014), and implies that the makers of such funding policies should be aware of the potential for conflict that clashing rationalities might entail.

\section{Acknowledgements}

We would like to thank all our interviewees and contact people in our study initiatives for their time and willingness to share their experiences with us, and Annabel Pinker for invaluable contributions to the data collection and insightful discussions. Annabel Pinker as well as three anonymous reviewers provided comments on earlier drafts of the manuscript. Esther Banks transcribed the Scottish interviews. This project has received funding from the European Union's $7^{\text {th }}$ Framework Programme for Research, Technological Development and Demonstration (Grant Agreement no. 603705) through TESS (Towards European Social Sustainability, http://www.tess-transition.eu/).

\section{References}

Aiken GT (2014) Common Sense Community? The Climate Challenge Fund's Official and Tacit Community Construction. Scottish Geographical Journal 130: 207-221.

Bäckstrand K and Lövbrand E (2006) Planting trees to mitigate climate change: Contested discourses of ecological modernisation, green governmentality and civic environmentalism. Global Environmental Politics 6: 50-75.

Baker LE (2004) Tending cultural landscapes and food citizenship in Toronto’s community gardens. Geographical Review 94: 305-325.

Baum, HS (2001) How should we evaluate community initiatives? Journal of the American Planning Association 67: 147-158. 
Bettencourt BA, Dillmann G and Wollman N (1996) The intragroup dynamics of maintaining a successful grassroots organization: A case study. Journal of Social Issues 52: 196186.

Bomberg E and McEwen N (2012) Mobilizing community energy. Energy Policy 51: 435444.

Borup M, Brown N, Konrad K and van Lente H (2006) The sociology of expectations in science and technology. Technology Analysis \& Strategic Management 18:285-298.

Ferris J, Norman C and Sempik J (2001) People, land and sustainability: Community gardens and the social dimension of sustainable development. Social Policy \& Administration 35: 559-568.

Foden M (2012) Everyday consumption practices as a site for activism? Exploring the motivations of grassroots reuse groups. People, Place and Policy Online 6: 1478-163.

Geels FW (2010) Ontologies, socio-technical transitions (to sustainability), and the multilevel perspective. Research Policy 39: 495-510.

Geels F and Raven R (2006) Non-linearity and expectations in niche-development trajectories: Ups and downs in Dutch biogas development (1973-2003). Technology Analysis \& Strategic Management 18:375-392.

Genus A, Cole A (2008) Re-thinking the multi-level perspective of technological transition. Research Policy 37: 1436-1445.

Ghose R and Pettygrove M (2014) Urban Community Gardens as Spaces of Citizenship. Antipode 46: 1092-1112.

Haggert C, Creamer E, Harnmeijer J, Parsons M and Bomberg E (2013) Community energy in Scotland: the social factors for success. The University of Edinburgh. Report for climateXchange. [URL] 
http://www.climatexchange.org.uk/files/4413/8315/2952/CXC_Report_-

_Success_Factors_for_Community_Energy.pdf.

Hajer MA (1993) Discourse coalitions and the institutionalization of practice: The case of acid rain in Britain. In: Fischer $\mathrm{F}$ and Forester $\mathrm{J}$ (eds.): The argumentative turn in policy analysis and planning. Duke University Press, Durham and London, pp. 43-76.

Hargreaves T, Hielscher S, Seyfang G and Smith A (2013) Grassroots innovations in community energy: The role of intermediaries in niche development. Global Environmental Change 23: 868-880.

Hibbert S, Piacentini M and Dajani H (2003) Understanding volunteer motivation for participation in a community-based food cooperative. International Journal of Nonprofit and Voluntary Sector Marketing 8: 30-42.

Hopkins R (2008) The transition handbook: from oil dependency to local resilience. Green Books, Totnes.

Kemp R and Loorbach D (2006) Transition management: A reflexive governance approach. In: Voß JP, Bauknecht D, and Kemp R (eds.): Reflexive Governance for Sustainable Development. Edward Elgar, Cheltenham, pp. 103-130.

Kemp R, Schot J and Hoogma R (1998) Regime shifts to sustainability through processes of niche formation: the approach of strategic niche management. Technology Analysis and Strategic Management 10: 175-196.

Kintrea K, St Clair R and Houston M (2015) Shaped by place? Young people’s aspirations in disadvantaged neighbourhoods. Journal of Youth Studies 18: 666-684.

Konrad K (2006) The social dynamics of expectations: The interaction of collective and actor-specific expectations on electronic commerce and interactive television. Technology Analysis \& Strategic Management 18: 429-444. 
Landini F, Long N, Leeuwis C and Murtagh S (2014) Theoretical Guidelines for a Psychology of Rural Development. Cuadernos de Desarrollo Rural 11: 125-147. http://dx.doi.org/10.11144/Javeriana.CRD11-74.tgpr

Levkoe CZ (2006) Learning democracy through food justice movements. Agriculture and Human Values 23: 89-98.

Markard J, Ravel R and Truffer B (2012) Sustainability transitions: An emerging field of research and its prospects. Research Policy 41: 955-967

Middlemiss L and Parrish BD (2010) Building capacity for low-carbon communities: The role of grassroots initiatives. Energy Policy 38: 7559-7556.

Moore T and McKee K (2013) The ownership of assets by place-based community organisations: Political rationales, geographies of social impact and future research agendas. Social Policy and Society 13: 521-533.

Pagès M, Fischer A. and Van der Wal R (in press) The dynamics of volunteer motivations for engaging in the management of invasive plants: Insights from a mixed-methods study on Scottish seabird islands. Journal of Environmental Planning and Management.

Parkhill KA, Shirani F, Butler C, Henwood KL, Groves C, Pidgeon NF (2015) ‘We are a community [but] that takes a certain amount of energy': Exploring shared visions, social action, and resilience in placed-based community-led energy initiatives. Environmental Science \& Policy 53: 60-69.

Rosol M (2012) Community Volunteering as Neoliberal Strategy? Green Space Production in Berlin. Antipode 44: 239-257.

Rydin, Y (2003) Conflict, consensus and rationality in environmental planning - An institutional discourse approach. Oxford University Press, Oxford, UK. 
Sarkissian W, Hofer N, Shore Y, Vajda S and Wilkinson C (2009) Kitchen Table

Sustainability: Practical Recipes for Community Engagement with Sustainability. Earthscan, London.

Scrase I and Smith A (2009) The (non-)politics of managing low carbon socio-technical transitions. Environmental Politics 18: 707-726.

Seyfang G and Smith A (2007) Grassroots innovations for sustainable development: Towards a new research and policy agenda. Environmental Politics 16: 584-603.

Seyfang G and Haxeltine A (2012) Growing grassroots innovations: exploring the role of community-based initiatives in governing sustainable energy transitions. Environment and Planning C 30: 381-400.

Seyfang G, Park JJ and Smith, A (2013) A thousand flowers blooming? An examination of community energy in the UK. Energy Policy 61: 977-989.

Seyfang G, Hielscher S, Hargreaves T, Martiskainen M and Smith A (2014) A grassroots sustainable energy niche? Reflections on community energy in the UK. Environmental Innovation and Social Transitions 13: 21-44.

Shove E and Walker G (2007) CAUTION! Transitions ahead: politics, practice, and sustainable transition management. Environment and Planning A 39: 763-770.

Smith A, Voß JP and Grin J (2010) Innovation studies and sustainability transitions: the allure of the multi-level perspective and its challenges. Research Policy 39: 435-448.

Smith A, Hargreaves T, Hielscher S, Martiskainen M and Seyfang G (2016) Making the most of community energies: Three perspectives on grassroots innovation. Environment and Planning A 48: 407-432.

Stirling A (2014) Emancipating Transformations: From controlling 'the transition' to culturing plural radical progress. STEPS Working Paper 64, STEPS Centre, Brighton. 
Strauss A and Corbin JM (1990) Basics of qualitative research: grounded theory procedures and techniques. Sage Publications, Thousand Oaks, US.

Tornaghi C (2014) Critical geography of urban agriculture. Progress in Human Geography 38: 551-567.

United Nations Conference on Sustainable Development (UNCSD) (2012) The future we want. United Nations Rio +20. [URL]: http://rio20.net/en/iniciativas/the-future-wewant-final-document-of-the-rio20-conference

Van der Schoor T and Scholtens B (2015) Power to the people: Local community initiatives and the transition to sustainable energy. Renewable and Sustainable Energy Reviews 43: 666-675.

Walker G and Devine-Wright P (2008) Community renewable energy: What should it mean? Energy Policy 36: 497-500.

Zipin L, Sellar S, Brennan M and Gale T (2015) Educating for futures in marginalized regions: A sociological framework for rethinking and researching aspirations. Educational Philosophy and Theory 47: 227-246. 
Table 1: Overview of study initiatives

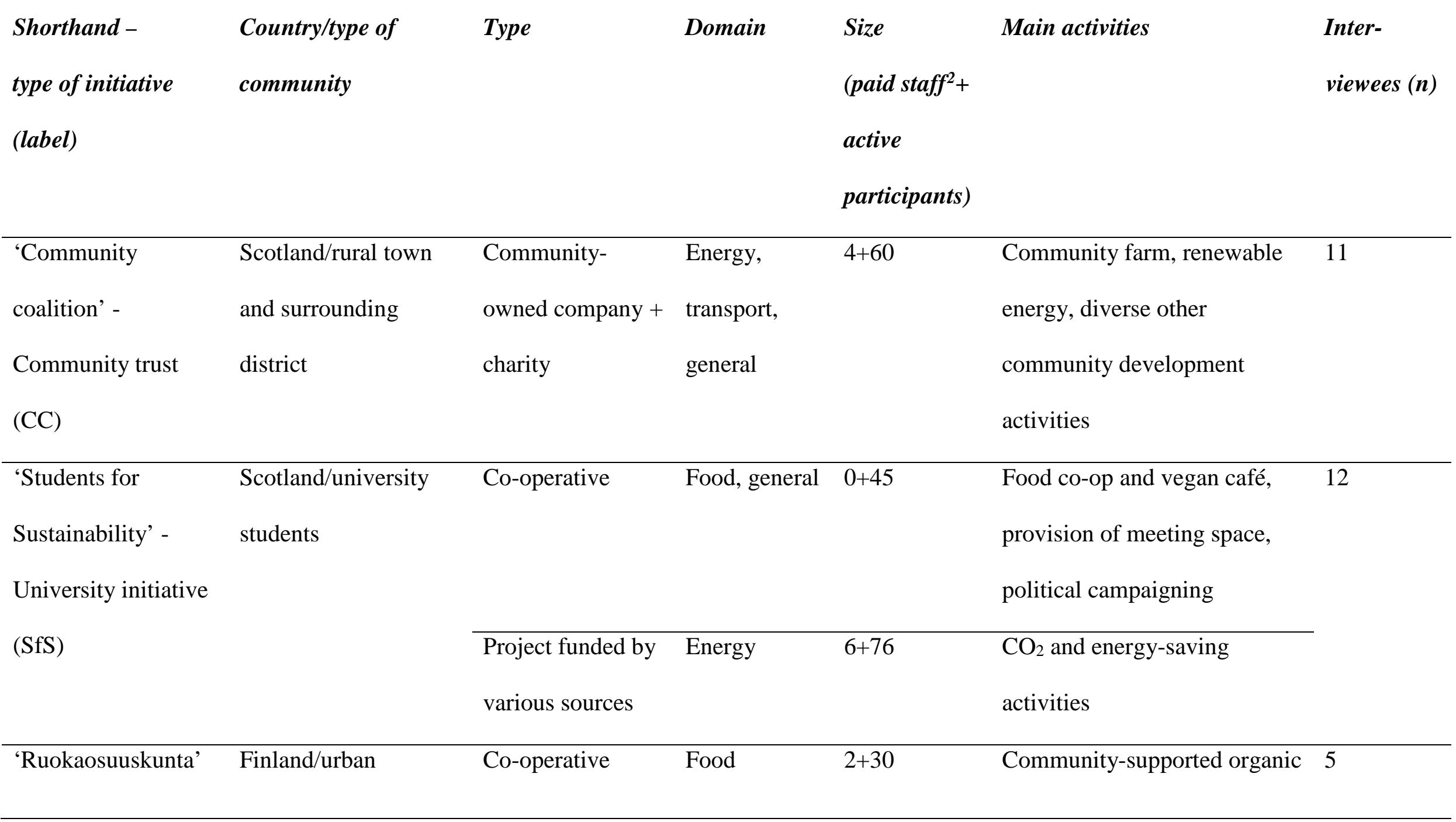

\footnotetext{
${ }^{2}$ Individuals, not full-time equivalent staff
} 
Agricultural co-op

(ROK)

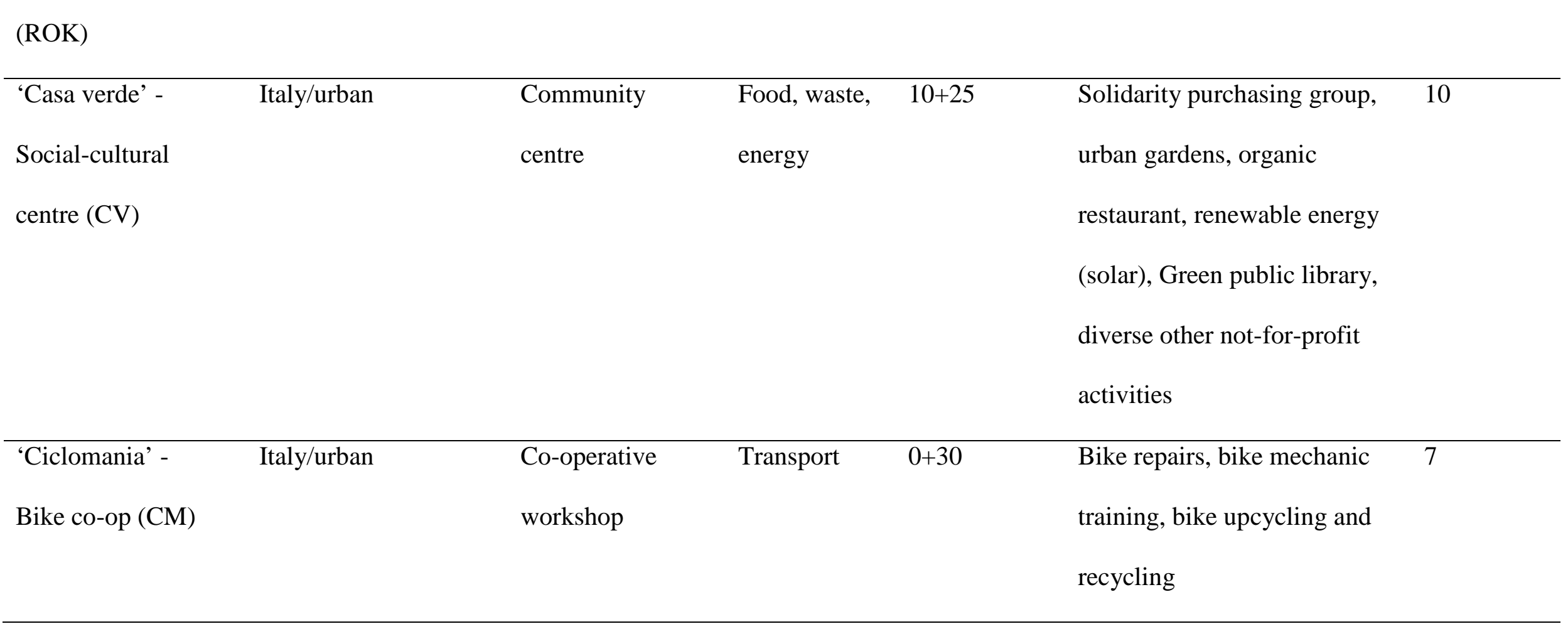

agriculture, vegetable growing 